\title{
Sympatric occurrence of four Cathartid vultures in the dry forests of north-western Peru
}

\author{
Robert S R Williams
}

Frankfurt Zoological Society and Asociación TuTierra. rob@szfperu.org

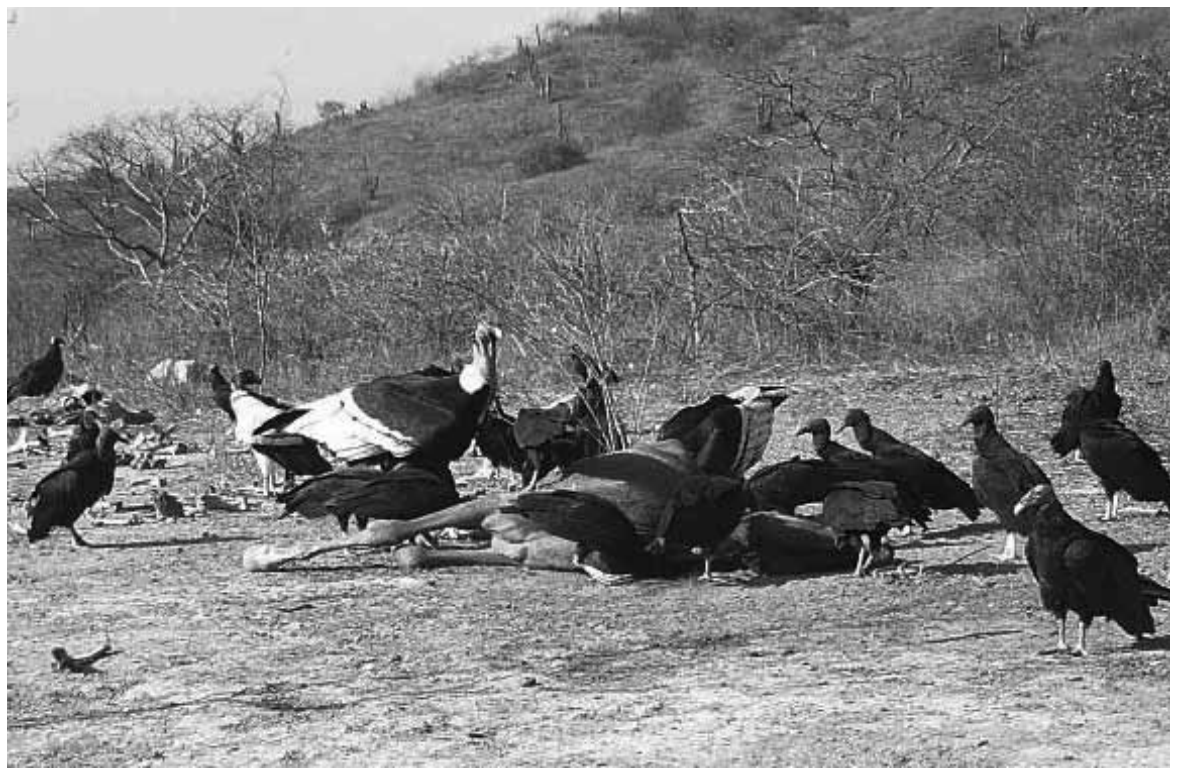

This photograph, taken with a cameratrap, shows four species of Cathartid vultures: Andean Condor Vultur gryphus, King Vulture Sarcoramphus papa, Turkey Vulture Cathartes aura and Black Vulture Coragyps atratus, feeding together on a horse carcass in the Chaparri Ecological Reserve in Lambayeque region, northwestern Peru. Chaparri Ecological Reserve is a community owned and managed Private Conservation Area of 34,412 hectares that was established in 2000 .
Both Andean Condors and King Vultures are becoming increasingly frequently seen within the reserve as wildlife populations recover from years of overgrazing and hunting.

Chaparri Reserve is located in the western foothills of the Andes where they meet the arid coastal lowlands. The vegetation here is sparse dry forest overing rolling hills, with evergreen gallery woodland along permanent water courses and higher mountains with large 
cliffs. The area is at the southern extent of the Tumbesian Endemic Bird Area (Stattersfield et al. 1998) and 45 restrictedrange bird species have been recorded in the reserve, many of them reaching their southern distributional limit here.

With only seven species of Cathartid vultures in the Americas and six of these occurring in South America there are few places where one can find such species diversity in one locality. Chaparri Reserve is one of only two areas in South America where it is possible to see the two largest and most spectacular South American species, the King Vulture and the Andean Condor, feeding together; the other being the dry valleys of the eastern Andes in Bolivia.

The King Vulture reaches its southernmost distributional limit to the west of the Andes here. The Andean Condor occurs in the Pacific lowlands of western South America, including coastal habitats, along the arid coast of Chile and Peru as far north as the Illescas peninsula (apprxoimately $200 \mathrm{~km}$ north-west of Chaparri); the species has declined in most of the Peruvian coast and is now patchily distributed with no recent records south of Chaparri for several hundred kilometres and only a small population remaining along the base of the Andes and on the Illescas peninsula.

Two subspecies of Turkey Vulture are visible in the photo, the individual in the right foreground is the subspecies jota and the individual at back left is of the Andean subspecies ruficollis; the migratory subspecies meridionalis also occurs seasonally in small numbers in the area. It is impossible to assign the Black Vultures in the photo to subspecies but it is most likely they are the lowland subspecies brasiliensis, which is the most common subspecies in the area, though occasionally birds are seen that appear to be of the Andean subspecies foetens.

\section{References}

Stattersfield, A. J., Crosby, M. J., Long, A. J. \& Wege, D. C. (1998) Endemic Bird Areas of the world: priorities for biodiversity conservation. Cambridge, UK: BirdLife International (Conservation Series No. 7). 